\title{
Unilateral Variations of Vessels and Nerves in the Neck
}

\author{
Variación Unilateral de Vasos y Nervios en el Cuello \\ "Nadire Unver Dogan; *Aynur Emine Cicekcibasi; **Zeliha Fazliogullari; \\ "Mehmet Tugrul Yilmaz; **Ismihan Ilknur Uysal \& *Ahmet Salbacak
}

\begin{abstract}
UNVER DOGAN, N.; CICEKCIBASI, A. E.; FAZLIOGULLARI, Z.; YILMAZ, M. T.; UYSAL, I. I. \& SALBACAK, A. Unilateral variations of vessels and nerves in the neck. Int. J. Morphol., 28(3):963-966, 2010.

SUMMARY: Variations of vessels and nerves in the left neck side, of 65 year old male cadaver, during the routine dissections, were detected. It was observed that the linguofacial trunk originated from external carotid artery and that the ascending pharyngeal artery originated from the occipital artery. It was determined that after the laryngeopharyngeales rami originated from the superior cervical ganglion, the branch wound around the origin of the superior thyroid artery. As an additional variation, the internal jugular vein divided. The cervical ansa and the inferior belly of the omohyoid muscle passed through the parts of the vein. We think that these type of variation can entail important difficulties during radiologic and surgical procedures of the neck region. To know these anatomical variations, is important for the anatomist and surgeons.
\end{abstract}

KEY WORDS: External carotid artery; Linguofacial trunk; Internal juguler vein; Anatomic variation.

\section{INTRODUCTION}

The external carotid artery is the main vessel which is provides blood support of the face and neck and separates from the common carotid artery on the upper side level of cartilago thyroidea. It lies upward and separates two end branches as maxillar and superficial temporal arteries in the retromandibular fossa (Moore, 1992; Standring, 2005). The superior thyroid, lingual and facial arteries arise from its anterior surface, the occipital and posterior auricular arteries arise from its posterior surface and the ascending pharyngeal artery arises from its medial surface (Standring).

The duramater vein sinuses and the face-neck veins drain to the internal jugular vein. The internal jugular vein is the neck's thickest (14-16 cm) vein which starts from foramen jugulare as the continuation of sinus sigmoideus. It takes place together with common carotid artery and vagal nerve within carotid vagina and forms brachiocephalic vein together with subclavial vein behind sternoclavicular joint (Standring). The internal jugular vein is one of two main vessels in the circulation of intracranial blood. Due to its superficial position, the internal jugular vein is an important anatomic superficial landmark which is used routinely
(Denys \& Uretsky, 1991; Asouhidou et al., 2008; Benter et al., 2001; Gadallah et al., 1995; Downie et al., 2007) in nephrology, oncology, cardiology and emergency service for the measuring of central venous pressure, giving the drugs, haemodialisis and parenteral nutrition (Downie et al.).

The large vascular abnormalities in the head-neck can stay without realizing during the whole life. These asymptomatic variations can become symptomatic in consequence of pathological situations such as atherosclerotic vascular diseases, aneurysms and senile changes. Therefore, important clinical problems can occur in surgical procedures (Zümre et al., 2005).

\section{CASE REPORT}

The variations of the branch origin of the external carotid artery, structure of the internal jugular vein and the course of the laryngeopharyngeal ramus were determined in the left neck side in the 65 years old male cadaver during

\footnotetext{
* Selcuk University, Meram Medical Faculty, Department of Anatomy, Konya, Turkey.

** Selcuk University, Selcuklu Medical Faculty, Department of Anatomy, Konya, Turkey.
} 
routine dissections. The facial and lingual arteries originated from anterior side of the external carotid artery as linguofacial trunk. The ascending pharyngeal artery was arised from occipital artery in $9.7 \mathrm{~mm}$ above of carotid bifurcatio (Fig. 1). The laryngeopharyngeal ramus which arised from superior cervical ganglion proceeded downforward crossing behind the external carotid artery. Then it wound around the initial section of the superior thyroid artery and continued towards up to pharynx (Fig. 2). In addition, the internal jugular vein was divided into two part (duplication) in $28.6 \mathrm{~mm}$ above clavicula. The inferior ramus of the cervical ansa and inferior venter of the omohyoid muscle passed between these two parts (Fig. 3).

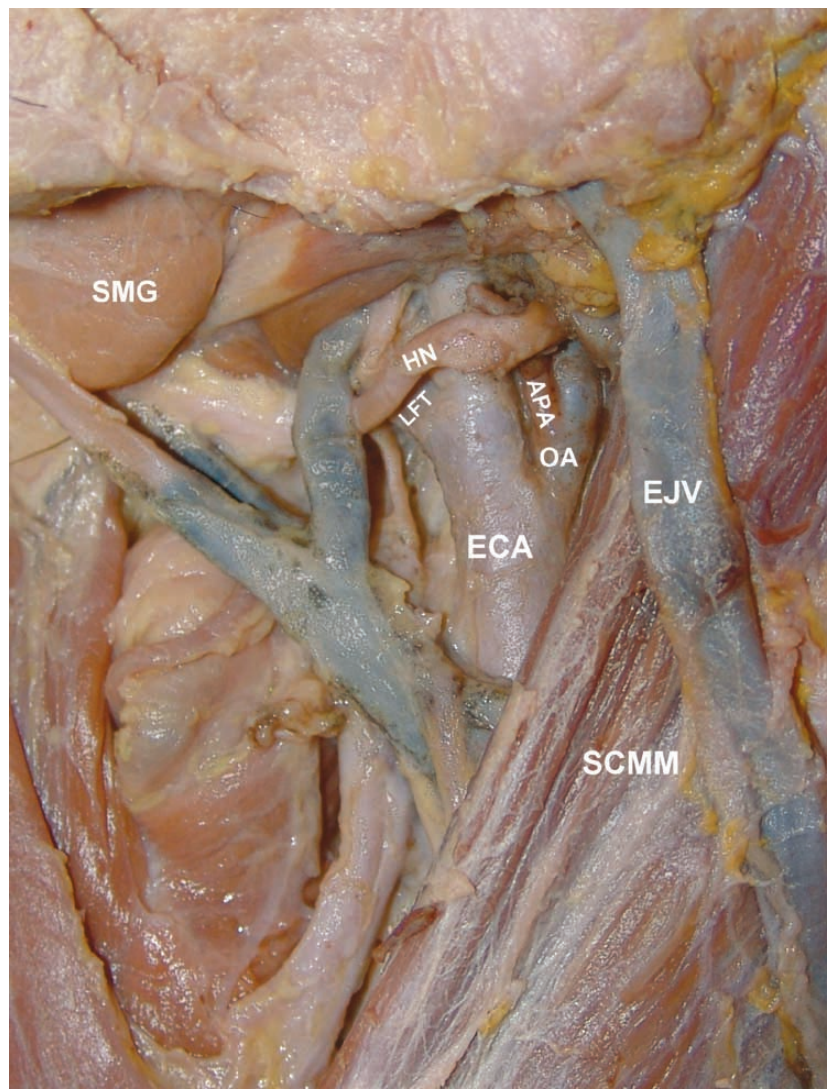

Fig. 1. In the left side of the neck, the linguofacial trunk (LFT) arised from anterior surface of the external carotid artery (ECA) and the ascending pharyngeal artery (APA) originated from the occipital artery (OA). SMG; Submandibular gland, SCMM; Sternocleidomastoid muscle, EJV; External jugular vein, HN; Hypoglossal nerve

\section{DISCUSSION}

The location of the carotid bifurcatio, the branching pattern of the external carotid artery and the variations of the branch origins are known quite well. These branches can

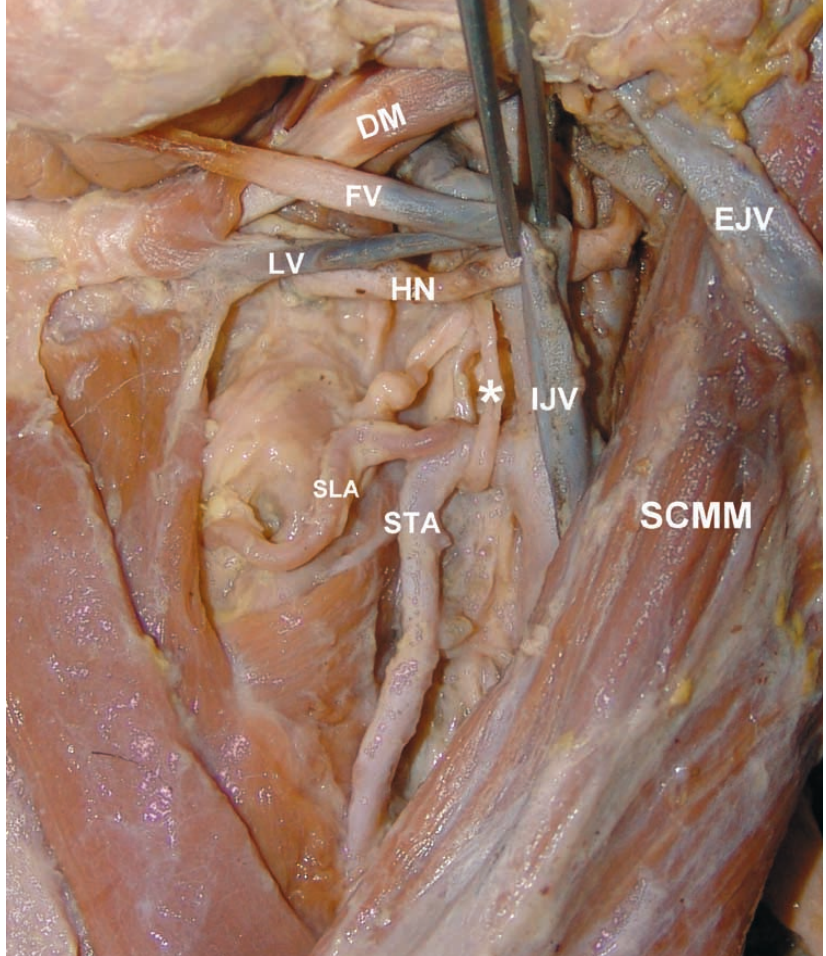

Fig. 2. The laryngeopharyngeal ramus (*) crossing behind the external carotid artery and coiling to the initial section of the superior thyroid artery (STA). SCMM; Sternocleidomastoid muscle, DM; Digastric muscle, IJV; Internal jugular vein, EJV; External jugular vein, HN; Hypoglossal nerve, SLA; Superior laryngeal artery.

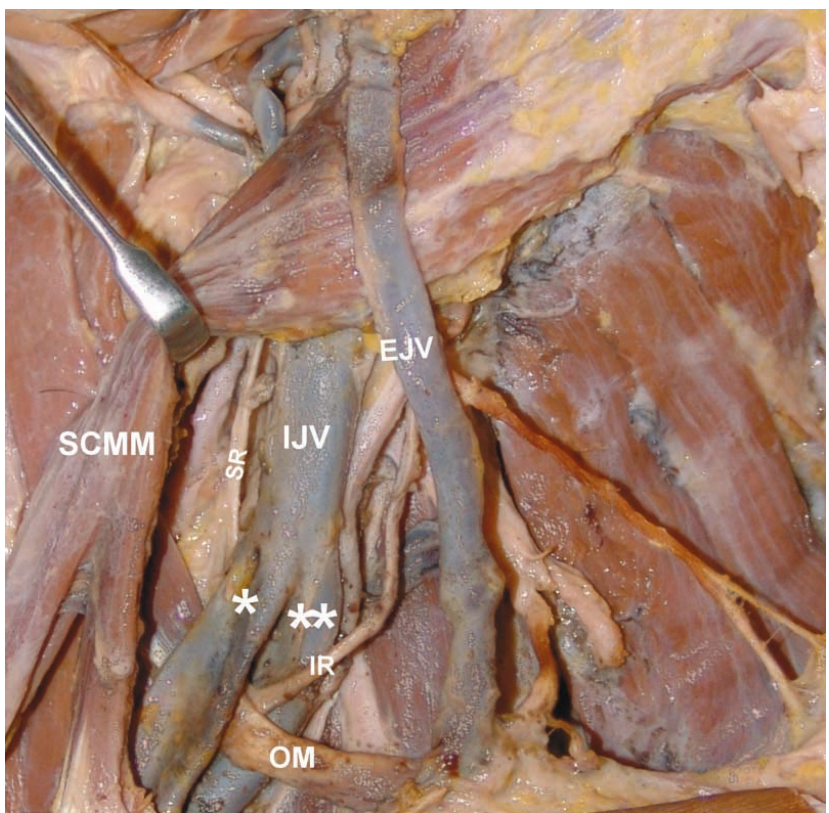

Fig. 3. The duplike internal jugular vein (IJV) and the inferior ramus of the cervical ansa (IR) and inferior venter of the omohyoid muscle (OM) which were passed between two parts. SCMM; Sternocleidomastoid muscle, EJV; External jugular vein, SR; Superior ramus, *; The first part of the internal jugular vein, **; The second part of the internal jugular vein. 
originate from a common trunk. There were the different trunk structures that the superior thyroid, lingual and facial arteries formed. Ozgur et al. (2008) classified the origins of these arteries which were arised from the external carotid artery in 4 types and reported their incidences. The separate origins of the arteries were defined as type 1 (in $90 \%$ of cases); the linguofacial trunk as type $2(7.5 \%)$; the thyrolingual trunk as type $3(2.5 \%)$; and thyrolinguofacial trunk as type 4 (Ozgur et al.). Yildirim et al. (2001) observed the total 6 (15\%) linguofacial trunk in 40 neck side (20 adult human cadavers). Zümre et al. reported linguofacial trunk in $20 \%$ of cases, thyrolinguofacial trunk in $2.5 \%$ and thyrolingual trunk in $2.5 \%$ in human fetuses. In this case, the linguofacial trunk that was originated from the external carotid artery in the left neck side, was observed.

Although the ascending pharyngeal artery arises from medial surface of the external carotid artery near of the origin of the occipital artery (Lasjaunias \& Moret, 1976), it was declared that this artery has different origins (Lang \& Heilek, 1984; Hacein-Bey et al., 2002; Aggarwal et al., 2006; Gluncic et al., 2001). Lang \& Heilek reported that the ascending pharyngeal artery originated from the external carotid artery in $80 \%$ of cases and from the branches of the external carotid artery in $20 \%$ of them. In some cases that this artery arised from internal carotid artery (Zümre et al.; Aggarwal et al.) or common carotid artery (Gluncic et al.). Hacein-Bey et al. said that the ascending pharyngeal artery originated from the proximal part of the occipital artery, as in our case.

The laryngeopharyngeal ramus which was arised from superior cervical ganglion proceeded down-forward crossing behind the external carotid artery. Then it wound around the initial section of the superior thyroid artery and continued towards up to pharynx. Nevertheless, according to our knowledge, there is no knowledge about course variations of the laryngeoopharyngeal ramus in the literature, it should be kept in mind that this variations can cause various clinical results no for two reasons. First, the nerve can be injured together with superior thyroid artery during thyroid surgery and the sympathetic innervation of pharynx can be damaged. Second, the superior thyroid artery blood flow may be affected because of the artery surrounded.

The dimension, localization and the anatomic variations of the internal jugular vein can be difficult the application of the central venous catheter and can lead to complications during the process. For this reason, the morphometric and topographic studies of the vein were made (Denys \& Uretsky; Lin et al., 1998). Lin et al., in 104 uremia patients, declared that the common carotid artery traced a tortuous course and passed over of the internal jugular vein in over 50\% 60 year old patients. In 200 patients using the two dimensional ultrasound, Denys \& Uretsky found that the internal jugular vein was the normal position in $92 \%$ of cases, in over $1 \mathrm{~cm}$ lateral from the common carotid artery in $1 \%$ and in medial in $2 \%$. They did not determine this vein in $2.5 \%$ of cases due to thrombus. In addition, it was smaller than normal in 3\% and its place was difficult to determine from outside by surface markers due to abnormal position in $5.5 \%$ (Denys \& Uretsky). The difficulty in determining the place of this vein was observed in $33 \%$ of 113 cancer patients (Benter et al.). Asouhidou et al. compared the dimensions of the internal jugular vein with the dimensions of the external jugular vein and common carotid artery in 186 cadaver neck side. They reported that the external jugular vein was larger than normal in 3 cases where the diameter of the internal jugular vein was smaller than $6 \mathrm{~mm}$.

The duplication and fenestration of the internal jugular vein are rarely observed and very similar each other. There is one vein passing from jugular foramen in both of them. The internal jugular vein separates into two in the duplication and drains to the subclavian vein proceeding as two veins while the separated vein reunits in the fenestration before opening to the subclavian vein (Downie et al). It is declared that the incidence of duplication is very low $(0.4 \%)$ in literature (Nayak, 2006). Prades et al. (2002) reported the fenestrated internal jugular vein $(2-5 \mathrm{~cm}$ length) in 3 cases (2 left, 1 right) during surgical procedures. In each case, it was observed that the internal jugular vein separated into two in the 1/3 upper part and reunited before draining to the subclavian vein. The lateral branch of the spinal accessorius nerve passed through parts of the vein (Prades et al.). Towbin \& Kanal (2004) determined the fenestrated internal jugular vein in left side-proximal part of 2 patients by angiographic computerized tomography. Downie et al. reported the duplikated internal jugular vein bilaterally at the level hyoid bone in the cadaver. The anterior rami of the C2-C3 spinal nerves and suprascapular artery passed between two parts of the vein at the right side whereas the omohyoid muscle passed at the left side. Muñoz Guerra et al. (2000) indicated that the omohyoid muscle passed between two parts of duplicated vein. In our study unlike the other studies, it was observed that the $1 / 3$ lower part of the internal jugular vein duplicated in the left neck side and passed the ramus inferior of the cervical ansa and the venter inferior of the omohyoid muscle between two parts. The variations are important because of the internal jugular vein is intensively used in clinical procedures.

Embryological origins of multiple variations of different structures cannot be informed absolutely. The multiple variations concerning the different structures such as vessel, nerve and muscle should be kept in mind before clinical applications. 
UNVER DOGAN, N.; CICEKCIBASI, A. E.; FAZliOgUllaRI, Z.; YILMAZ, M. T.; UYSAL, I. I. \& SALBACAK, A. Caso de variación unilateral de vasculatura y nervio en la región del cuello. Int. J. Morphol., 28(3):963-966, 2010.

RESUMEN: Durante una disección de rutina, fue obserada en el lado izquierdo del cuello de un cadáver de sexo masculino de 65 años de edad variaciones anatómicas vasculares y nerviosas. Se observó que el tronco linguofacial se originaba de la arteria carótida externa y que la arteria faríngea ascendente se origina en la arteria occipital. Se determinó que los ramos laringofaríngeos originadas desde el ganglio cervical superior, giraban en torno al origen de la arteria tiroidea superior. Como una variación adicional, la vena jugular interna se encontró dividida. El asa cervical y el vientre inferior del músculo omohioideo pasaban a través de las partes de la dividión de la vena. Creemos que este tipo de variaciones supone dificultades importantes durante procedimientos radiológicos y quirúrgicos de la región del cuello, y por tanto, es importante que los cirujanos conozcan estas variaciones.

PALABRAS CLAVE: Arteria carótida externa; Tronco linguofacial; Vena yugular interna; Variación anatómica.

\section{REFERENCES}

Asouhidou, I.; Natsis, K.; Asteri, T.; Sountoulides, P.; Vlasis K. \& Tsikaras P. Anatomical variation of left internal jugular vein: clinical significance for an anaesthesiologist. Eur. J. Anaesthesiol., 25(4):3148, 2008 .

Aggarwal, N. R.; Krishnamoorthy, T.; Devasia, B.; Menon, G. \& Chandrasekhar, K. Variant origin of superior thyroid artery, occipital artery and ascending pharyngeal artery from a common trunk from the cervical segment of internal carotid artery. Surg. Radiol. Anat., 28(6):650-3, 2006.

Benter, T.; Teichgräber, U. K.; Klühs, L.; Papadopoulos, S.; Köhne, C. H.; Felix, R. \& Dörken, B. Anatomical variations in the internal jugular veins of cancer patients affecting central venous access. Anatomical variation of the internal jugular vein. Ultraschall Med., 22(1):23-6, 2001.

Denys, B. G. \& Uretsky, B. F. Anatomical variations of internal jugular vein location: impact on central venous access. Crit. Care. Med., 19(12):1516-9, 1991.

Downie, S. A.; Schalop, L.; Mazurek, J. N.; Savitch, G.; Lelonek, G. J. \& Olson, T. R. Bilateral duplicated internal jugular veins: case study and literature review. Clin. Anat., 20(3):260-6, 2007.

Gadallah, M. F.; White, R.; Vickers, B.; el-Shahawy, M. \& Work, J. Awareness of internal jugular, subclavian, superior vena cava and femoral venous anomalies may reduce morbidity of acute venous catheter procedures. Clin. Nephrol., 44(5):345-8, 1995.

Gluncic, V.; Petanjek, Z.; Marusic, A. \& Gluncic, I. High bifurcation of common carotid artery, anomalous origin of ascending pharyngeal artery and anomalous branching pattern of external carotid artery. Surg. Radiol. Anat., 23(2):123-5, 2001.

Hacein-Bey, L.; Daniels, D. L.; Ulmer, J. L.; Mark, L. P.; Smith, M. M.; Strottmann, J. M.; Brown, D.; Meyer, G. A. \& Wackym, P. A. The ascending pharyngeal artery: branches, anastomoses, and clinical significance. AJNR. Am. J. Neuroradiol., 23(7):1246-56, 2002.

Lasjaunias, P. \& Moret, J. The ascending pharyngeal artery: normal and pathological radioanatomy. Neuroradiology, 11(2):77-82, 1976.

Lang, J. \& Heilek, E. Anatomo-clinical findings on the ascending pharyngeal artery. Anat. Anz., 156(3):177-207, 1984.
Lin, B. S.; Kong, C. W.; Tarng, D. C.; Huang, T. P. \& Tang, G. J. Anatomical variation of the internal jugular vein and its impact on temporary haemodialysis vascular access: an ultrasonographic survey in uraemic patients. Nephrol. Dial. Transplant., 13(1):134-8, 1998.

Moore, K. L. Clinically Oriented Anatomy. $3^{\text {th }}$ Ed. Baltimore, Williams \& Wilkins, 1992. pp. 805-7.

Muñoz Guerra, M. F.; Campo, F. R.; Gías, L.N. \& Díaz González, F. J. Double internal jugular vein. Plast. Reconstr. Surg., 106(6):1434-5, 2000.

Nayak, B. S. Surgically important variations of the jugular veins. Clin. Anat., 19(6):544-6, 2006.

Ozgur, Z.; Govsa, F. \& Ozgur, T. Assessment of origin characteristics of the front branches of the external carotid artery. J. Craniofac. Surg., 19(4):1159-66, 2008.

Prades, J. M.; Timoshenko, A.; Dumollard, J. M.; Durand, M.; Merzougui, N. \& Martin, C. High duplication of the internal jugular vein: clinical incidence in the adult and surgical consequences, a report of three clinical cases. Surg. Radiol. Anat., 24(2):129-32, 2002.

Standring, S. M. (Ed.). Gray's Anatomy. 39 $9^{\text {th }}$ Ed. Edinburgh, Elsevier, Churchill Livingstone, 2005. pp. 543-52.

Towbin, A. J. \& Kanal, E. A review of two cases of fenestrated internal jugular veins as seen by CT angiography. AJNR. Am. J. Neuroradiol., 25(8):1433-4, 2004.

Yıldırım, M.; Tanyeli, E.; Soyluoglu, A. I' \& Tuna, Y. Truncus linguofacialis sıklıg 1. Morfoloji Der., 9(1):33-4, 2001.

Zümre, Ö.; Salbacak, A.; Ciçekcibasi, A. E.; Tuncer, I. \& Seker, M. Investigation of the bifurcation level of the common carotid artery and variations of the branches of the external carotid artery in human fetuses. Ann. Anat., 187(4):361-9, 2005.

Correspondence to:

Nadire Unver Dogan

Selcuk University

Meram Medical Faculty

Department of Anatomy

Konya

TURKEY

Email: nunver2003@yahoo.com

Received:13-11-2009

Accepted:12-03-2010 